\title{
The use of graphs in annual reports of major
} Italian companies

\section{Giuseppe lanniello}

University of Tuscia,

Viterbo, Italy

E-mail: ianniell@unitus.it

\begin{abstract}
This paper shows the potential benefits and risks, in terms of communication, involved in the use of graphs in corporate annual reports. An empirical analysis is conducted on the year 2005 annual reports of 52 Italian listed companies with higher capitalisation. Its main findings are as follows: the vast majority of firms included in our sample use graphs in annual reports; topics graphed in the Anglo-Saxon area, such as EPS, DPS, cash flow and ROCE, are largely absent in the Italian graphical language, showing similarities with the case of Germany; evidence on the selectivity hypothesis tends in the direction expected but no significant association was found; about one-quarter of key performance indicator graphs are materially distorted; graphical alterations that are favourable to the firms are relatively more frequent than those that are unfavourable; and financial graphs exhibit slope parameters that depart materially from the optimum.
\end{abstract}

Keywords: accounting communication; corporate annual reports; graphs; Italian listed companies.

Reference to this paper should be made as follows: Ianniello, G. (2009) 'The use of graphs in annual reports of major Italian companies', Int. J. Accounting, Auditing and Performance Evaluation, Vol. 5, No. 4, pp.442-462.

Biographical notes: Giuseppe Ianniello $(\mathrm{PhD})$ is a full-time professor of Economia Aziendale (Accounting and Business Administration) at the School of Economics, University of Tuscia, Viterbo, Italy, where he teaches undergraduate and graduate level courses in financial accounting and auditing. His research deals with international accounting, financial reporting, accounting communication and accounting history.

\section{Introduction}

In recent years, the use of photographs, images, colours and graphics in corporate annual reports has become widespread. This practice can be seen as the emergence of new syntactic elements, which contribute to the construction of annual reports as a means of communication, oriented to various stakeholders in certain economic, social and cultural contexts (Lee, 1994; Catturi and Riccaboni, 1996; Hopwood, 1996; Preston, Wright and Young, 1996; Courtis, 2004; Beattie, Dhanani and Jones, 2008). In particular, the issue of financial graphs has emerged during the last 20 years as an important area in accounting research: Studies have been conducted at the national and international levels (e.g. see Section 3). However, the use of financial graphs in Italy in particular has been neglected. 